\title{
DEZ TRABALHOS DE ARTE INDÍGENA QUE MUDARAM A FORMA COMO IMAGINAMOS NÓS MESMOS ${ }^{1}$
}

\author{
10 INDIGENOUS ARTWORKS THAT CHANGED HOW WE \\ IMAGINE OURSELVES
}

Richard Hill ${ }^{2}$

Em março de 2016, afirmei que o melhor da Arte Indígena entre 1980 e 1995 "mudou o modo como imaginamos nós mesmos e nosso lugar no mundo" e, agora, gostaria de compartilhar os dez trabalhos que tiveram esse efeito sobre mim. Eu poderia ter feito outra lista, do mesmo tamanho e com outros artistas e trabalhos, mas estes foram os que tiveram uma importância especial para mim ao longo dos anos. Eles tocam todos os temas e estratégias-chave que definem esse período: revitalização da cultura, insistência na validade da experiência contemporânea, uso do humor, crítica da representação colonial e da apropriação cultural, reivindicação por espaços na esfera pública, preocupação com a terra, crítica institucional, contra-histórias, questionamento sobre o lugar social da mulher e exploração do desempenho da identidade.

Esses trabalhos, e outros assim como esses, definiram esses temas de modo tão eficaz que é continuamente difícil lembrar o quão radical e desbravadores eles foram quando apareceram num primeiro momento. Uma das vantagens de fazer uma lista é que nos força a fazer escolhas difíceis sobre o que é importante, ajudando a esclarecer como valoramos um trabalho. O leitor, por outro lado, não está sob nenhuma restrição e se encontra livre para contemplar - talvez com frustração - os muitos trabalhos favoritos que ficaram de fora. Sendo assim, o outro valor de fazer

1 Ensaio originalmente publicado em Canadianart, em 28 de abril de 2016.

2 Pesquisador em Estudos Indígenas da Universidade de Arte e Design "Emily Carr", Vancouver, Canadá. 
uma lista é a contemplação da inevitável inadequação (prefiro imperfeição) de listas e a geração de desejos de pensar além delas.

Aqui vai minha lista em ordem cronológica:

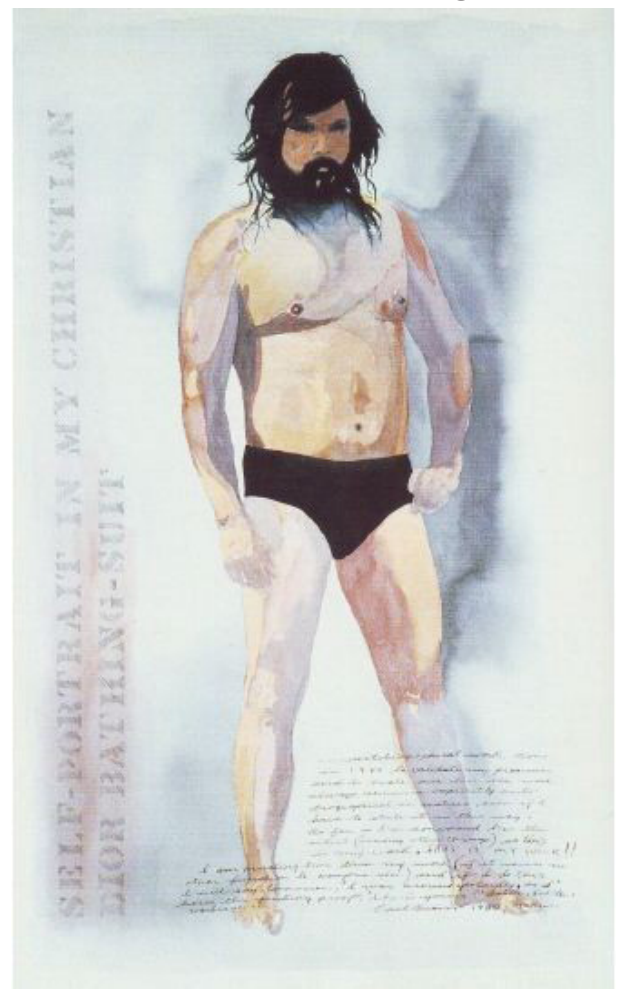

1- Carl Beam, Self-Portraitin My Christian Dior Bathing Suit, 1980 [Autorretrato com a minha roupa de banho, Christian Dior]

Embora eu estivesse tentado a incluir uma de suas distintas colagens dissolvedoras-de-tempo, não pude resistir a este desafiador autorretrato, que dá início à nossa cronologia em 1980. Beam explicou que estava deliberadamente tentando subverter as expectativas do público da arte daquele momento. Ele deu ao público a, que provavelmente esperava que artistas Anishinaabe produzissem dentro do estilo então conhecido como “Woodland School' (se é que esperavam a alguma coisa), uma potente dose de realidade contemporânea. E em aquarela!

Em nosso mundo pós-metrossexual o consumo de grifes por homens já foi assimilado, mas em 1980, roupas de banho de grifes masculinas 
eram anunciadas prioritariamente para os jovens da classe emergente que ficariam conhecidos como "yuppies". Uma escritora discutindo esse trabalho em 1980 supôs que seus leitores entenderiam que um "índio" provavelmente não pertenceria a essa classe.

Com sua barba e cabelo longos e hippies, a postura ereta e o olhar firme, Beam parece estar nos desafiando a rir e, igualmente, nos desafiando a não rir. Em ambos os casos, ficamos nos perguntando o que há de tão engraçado num "índio" usando uma sunga de grife.

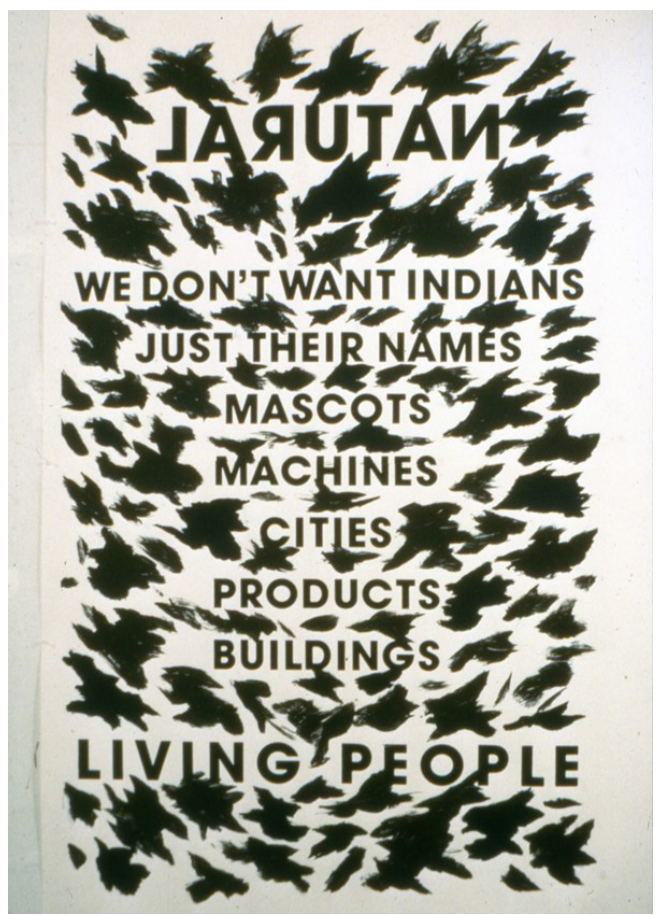

2- Edgar Heap of Birds, Don't Want Indians, 1982 [Não quer indígenas]

Eu hesitei antes de escolher esse trabalho textual primevo de Heap no lugar da série mais conhecida Native Hosts (Anfitriões Nativos), que fez potentes reivindicações pelo espaço público e pelas contra-histórias. Mas apenas porque aquele trabalho já é tão conhecido, eu tendi na direção de uma escolha mais pessoal, um dos primeiros trabalhos desse artista, sobre o qual me lembro de ter refletido muito enquanto jovem estudante de arte.

Foi a primeira vez que vi um artista Indígena fazendo um trabalho 
conceitual baseado em texto, fico um pouco envergonhado de dizer que isso era excitante por si só. Porém, o mais importante era a habilidade do artista em dizer tanto com tão poucas palavras, estabelecendo um ritmo implacável e convincente, que é radicalmente interrompido na última linha.

O trabalho é obscuro, e infelizmente diz a verdade sobre a apropriação e o consumo de signos e símbolos de culturas originárias. Ele começa com o espelhamento da palavra "NATURAL", sugerindo que nós somos consumidos e comercializados como "filhos da natureza" ou nobres selvagens, e que não há nada de natural nessa construção.

Nomes indígenas são bem vindos, mas quando chegamos a pergunta final "PESSOAS VIVAS?" - nós já conhecemos a resposta. A esfera pública na qual o artista pretende inserir seu trabalho já decidiu que não há espaço para povos Indígenas contemporâneos. Mas o primeiro passo para abrir espaço é definir os termos de sua exclusão.

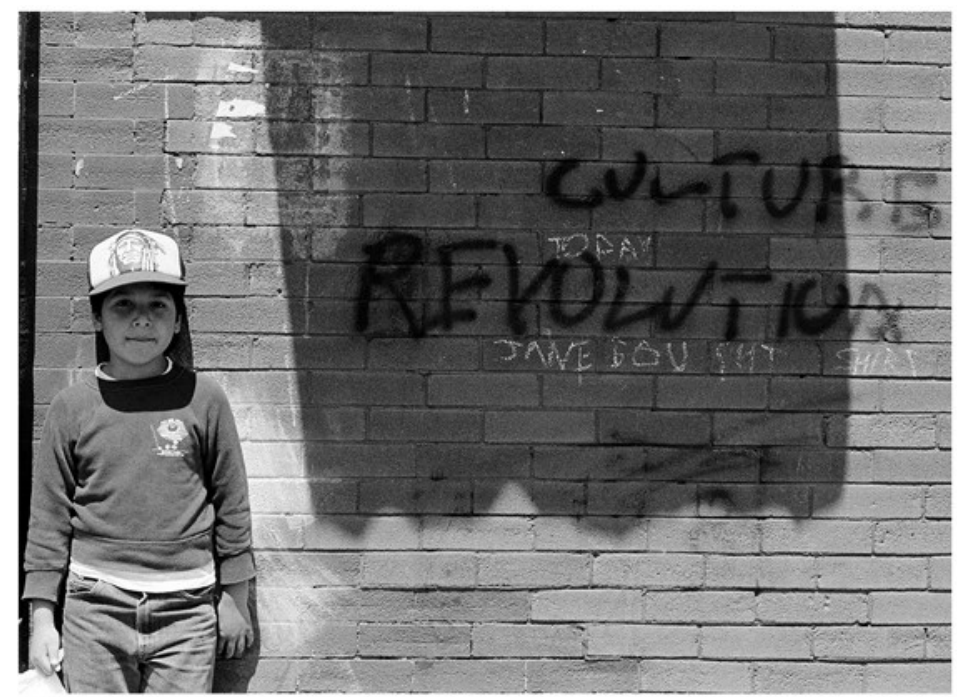

3- Jeff Thomas, Culture Revolution (Bear Series), Toronto, Ontario, 1984 [Revolução Cultural, (Série Bear)]

Para mim, Jeff Thomas é, primeiramente, um pesquisador e seus principais temas são a história da representação Indígena e a experiência Indígena contemporânea: como estes dialogam e como podem ser reconfigurados pelo agenciamento do artista. Sua principal ferramenta de 
pesquisa é a câmera, e ele é preciso em localizarseus sujeitos na rua ou em arquivos. Como os melhores pesquisadores, ele se faz perguntas reais sem presumir que já sabe a resposta de antemão. Como sua audiência, nós o acompanhamos e aprendemos com ele.

Uma vez que escolhe um assunto, Thomas tende a não abandoná-lo, revisitando-o repetidas vezes, investigando como ele é percebido a cada nova perspectiva. Eu não posso escapar de fazer o mesmo revisitando Culture Revolution, o primeiro da série de retratos em processo do seu filho Bear. Aqui, Bear ainda menino, veste um boné de baseball, grande demais para ele, com um retrato feito por Edward Curtis do líder Cheyenne Two Moons (Duas Luas). O pedaço de um graffiti nos arredores da Queen Street de Toronto aponta a revolução que Thomas está ao mesmo tempo documentando e ajudando a criar.

Bear eventualmente veio a crescer naquele boné. É possível que você o conheça como o DJ Bear Witness de A Tribe Called Red. Na verdade, quando mencionei Thomas na sala de aula esse ano, um estudante perguntou, “esse cara não é o pai do Bear Witness?” Eu duvido que Jeff se importaria. É assim que percebemos revoluções bem-sucedidas.

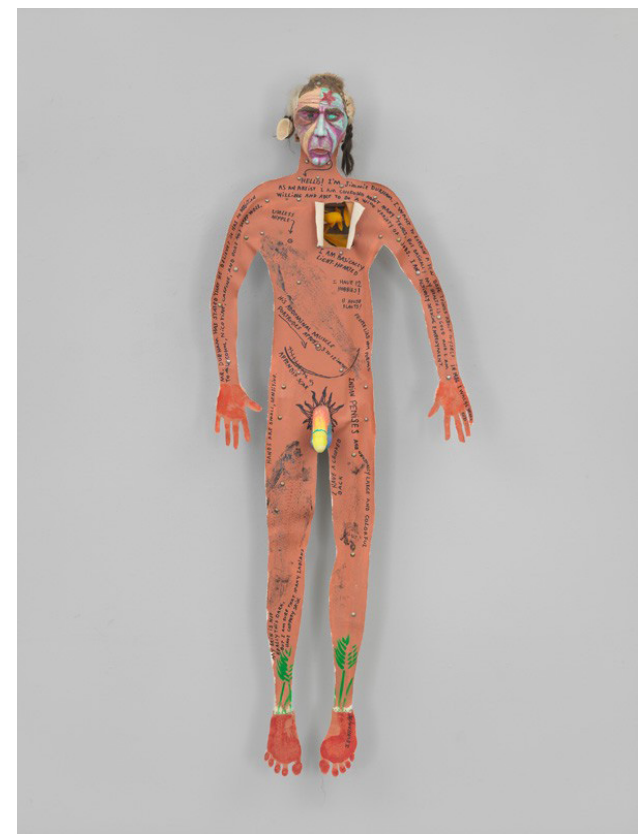

4- Jimmie Durham, Self-Portrait, 1986 (Whitney Museum of American Art, New York). 
Existem outros trabalhos de Durham desse período que eu acho mais desafiadores - o Caliban Codex me vem à mente -, mas nenhum deles destila tão concisamente a crítica do "índio imaginário" em um único corpo conturbado.

Roberta Smith, crítica do New York Times, certa vez afirmou que os trabalhos feitos por Durham nesse período têm como convicção a sentença: "minhas raízes minha arte". Ainda assim esses trabalhos de Durham não são sobre sua herança ou identidade, exceto no caso daquela identidade previamente definida pelos outros, sujeita a ataques irônicos por parte do artista. Desde o começo da modernidade, os autorretratos têm prometido uma janela para uma identidade pessoal autêntica, mas nesse caso, ele proporciona apenas "uma máscara" que "mascara uma não-identidade", nas palavras de Jean Fisher.

Trata-se de uma tela cortada na forma de um corpo, com depoimentos sobre o artista na primeira e na terceira pessoa rabiscados por toda parte. Eles vão do bobo e mundano: "Eu tenho 12 hobbies! 11 plantas dentro de casa!", ao estereotipado absurdo: "pênis indígenas são geralmente grandes e coloridos?" A última afirmação é ilustrada por um pênis grande e colorido entalhado. Isso significa que girando a partir dessas declarações duvidosas (nenhuma das quais é possível verificar) para os elementos tridimensionais da escultura, não nos movemos do superficial ao profundo, apenas revelamos outras superfícies, mais profundas, porém igualmente indóceis.

Lê-se "I am basically light hearted" (expressão em inglês que pode ser traduzida por "Eu basicamente tenho um coração leve"). Seu peito está aberto e, passando por algumas costelas, podemos olhar lá dentro e vermos com nossos próprios olhos. No lugar de seu coração, estão algumas penas pintadas de vermelho vivo, do tipo que encontraríamos no cocar de brinquedo de uma criança. 


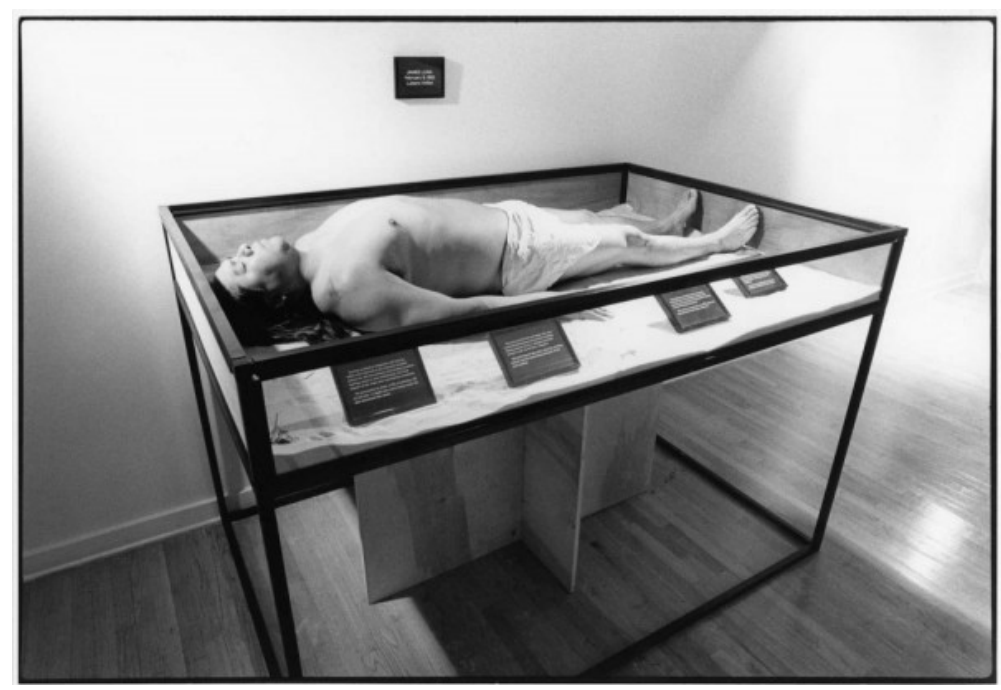

5- James Luna, Artifact Piece, 1987.

A Crítica institucional foi um movimento que lutou em muitas frentes de batalha, mas nenhuma manobra foi mais devastadora que "Artifact Piece", de Luna. É uma brilhante reductio ad absurdum de exibições de pessoas indígenas em museus (e de atitudes direcionadas a pessoas indígenas em geral). Luna realizou a performance apenas duas vezes: a primeira no San Diego Museum of Man e depois, em 1990, para a "Decade Show", em Nova York. Em cada execução, ele instalou a si mesmo numa vitrine de museu junto com itens pessoais que refletiam sua gama de interesses, da literatura beat à "música indígena, country e ocidental, clássicos, pop e rock, coisas novas - ouço tudo". Como ele próprio afirmou:

Eu sou um homem nativo, nascido em 1950, que não nasceu dentro de uma tepee (tendas construídas por alguns dos Povos Originários norte-americanos), mas que foi criado em frente a uma TV. Eu sou um homem que foi a faculdade... Quero falar com todo mundo que também foi criando em frente a uma TV. Eu quero falar com você como uma pessoa inteira, e trazer meu lado cultural também.

O trabalho revelou não só o olhar colonial aquisitivo e o que Jean Fisher descreveu como "os códigos necrófilos do museu", mas também o absurdo de sua missão de representar culturas inteiras através de alguns artefatos bem escolhidos. E se exibir um corpo vivo parece absurdo, 
precisamos apenas apontar para a história de exibições ao vivo de pessoas Indígenas, dos primeiros cativos de Colombo até as feiras internacionais do final do século XIX e início do século XX. Nosso impulso é certamente o mesmo de um visitante Indígena à exposição, que segundo Luna ficava ao lado dele dizendo: "Levante-se, ei, se levante..."

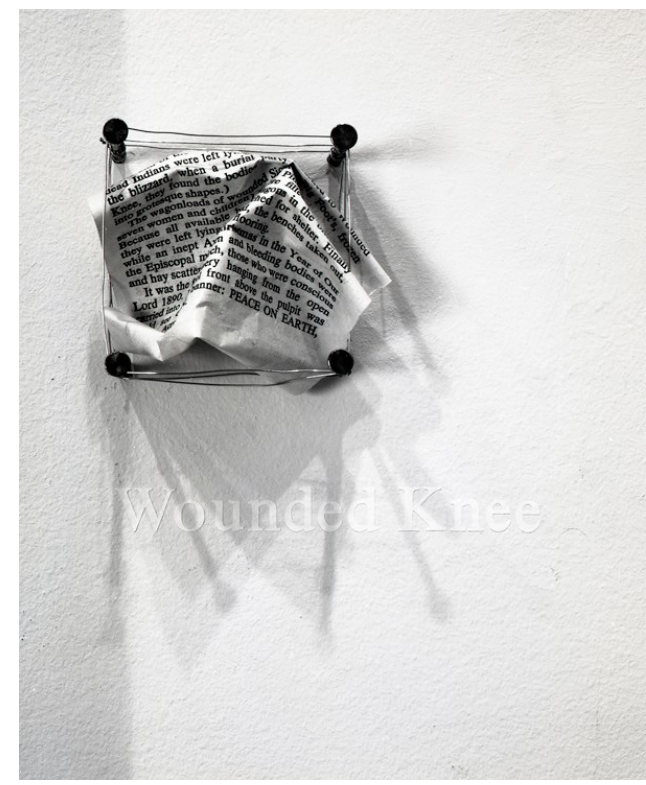

6- Edward Poitras, Small Matters, 1988

Eu fiquei tentado a incluir um das esculturas de coiotes de Poitras aqui - elas são tão interessantes visualmente - mas este trabalho evidencia o conceitualismo sutil que é uma parte muito importante de sua prática. Às vezes, se caracteriza pelo gesto aparentemente displicente ou pelo item posto de lado que o espectador gradualmente percebe como sendo repleto de significado. E por um uso do espaço que sugere tanto a reivindicação expansionista do espaço da parede, típico do trabalho de arte moderna, quanto a atitude generosa em relação ao espaço da estética da Pradaria. É uma generosidade que tanto exige quanto recompensa a atenção cuidadosa. Mas não se deixe enganar pelo tamanho e economia de materiais. Quando você se aproxima para compartilhar o espaço íntimo do trabalho, você sentirá um impacto muito forte.

O trabalho consiste em quatro páginas do livro mais vendido de Dee 
Brown, em 1970, Enterrem meu coração na curva do Rio, amassado em bolas de papel, com o texto ainda parcialmente legível, montado espaçadamente na parede entre quatro pregos salientes, de cabeça chata, organizados num quadrado e envolvidos por um arame. Abaixo de cada um há um texto de cor branca, quase imperceptível na parede branca. Brown foi provavelmente o primeiro escritor popular da história dos Estados Unidos a tratar os povos indígenas com empatia e o trabalho conclui-se com uma descrição do massacre de Wounded Knee.

Uma coisa pequena e pouco visível é que cada página, aparentemente descartada, é recuperada e encaixada entre os pregos: branco no branco, como uma pintura modernista tardia ou como se estivessem congelados, como órgãos cobertos pela neve em Wounded Knee.

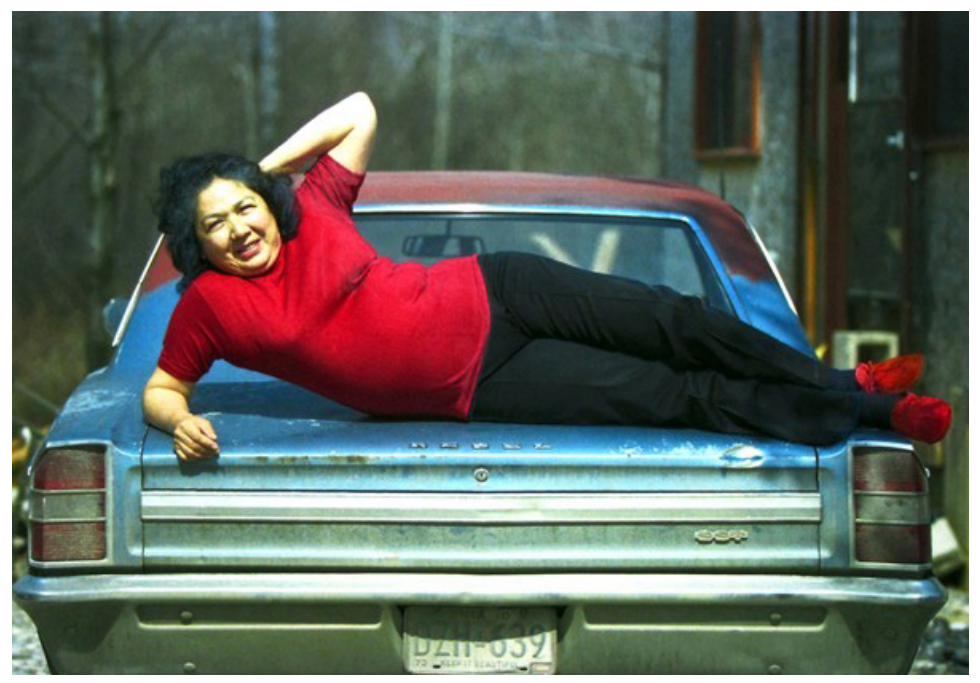

7- Shelley Niro, The Rebel, 1991.

Soa ridículo, mas antes de ver a exposição "Mohawks in Beehives", de Shelley Niro, na Mercer Union, em 1991, eu não percebia que identidade indígena poderia ser tratada - publicamente - como uma oportunidade para atravessar os limites do jogo performativo. Eu sei que temos muitas pessoas engraçadas em nossas comunidades, e que esse tipo de jogo acontece regularmente no dia a dia, mas ser um Indígena no espaço público parecia algo sério, envolvendo performances previsíveis. Niro 
mudou tudo isso e pavimentou o caminho para que outros personagens extravagantes e destruidores de alegorias fossem em seguida levados ao palco por artistas como Lori Blondeau, Kent Monkman e Terrance Houle.

De acordo com Niro, esse trabalho foi um ato de libertação que nasceu da tensão de acompanhar a primeira Guerra do Golfo e a defesa de Kanesatake pelos Mohawk contra a polícia do Quebec e também do exército Canadense (popularmente conhecido como Oka crisis). Recusandose a aceitar o papel de vítima, Shelley Niro e suas irmãs adotaram vários personagens "cafonas" e, como ela mesma diz, "invadiram o centro de Brantford”. O registro fotográfico dessa excursão foi um lembrete oportuno do poder que as mulheres Indígenas poderiam exercer tomando o controle de sua própria representação e aproveitando os jogos de desejos que impulsionam alegorias culturais para novos e deliciosos fins. Seria preciso um coração de pedra para ver The Rebel [A rebelde] e não ser seduzido.

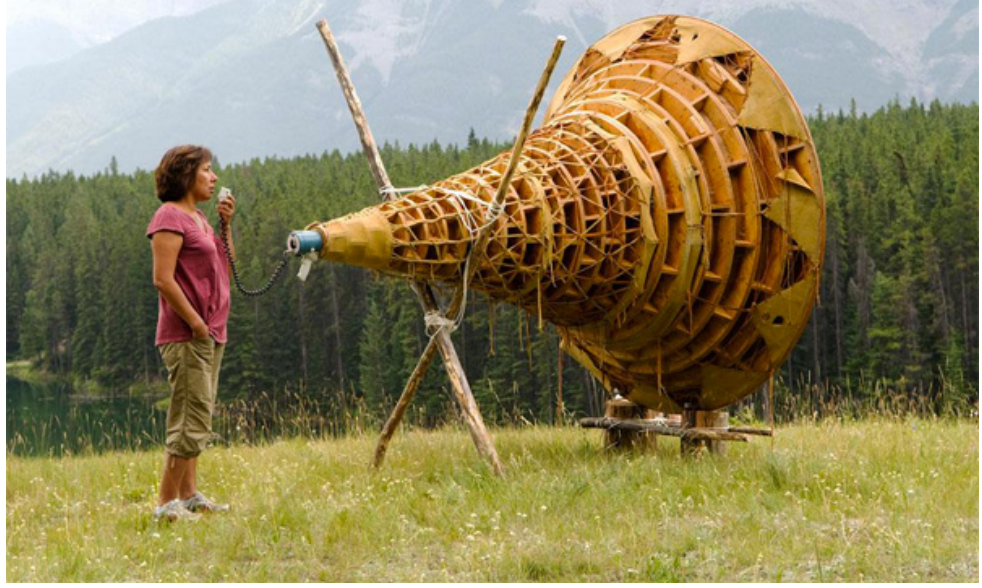

8- Rebecca Belmore, Ayum-ee-aawachOomama-mowan: Speaking to their Mother, 1991.

Outra cria da defesa Mohawk de Kanesatake, o enorme megafone de Belmore é uma brilhante peça de ativismo/propaganda política que estabeleceu sua preocupação constante com a vulnerabilidade vivida por aqueles que foram silenciados. Belmore mostrou esse trabalho em todo o 
país para literalmente dar voz às muitas comunidades indígenas que sem isso permaneceriam efetivamente silenciadas na esfera pública.

Eu não consigo pensar em outro trabalho que tenha motivado participações tão entusiasmadas de fora do mundo da arte e, ao mesmo tempo, também tenha ressoado como arte com um permanente, amplo e poético espectro de significados. Muito do trabalho que tem sido feito desde então com ambições participativas semelhantes - com frequência sob o guarda-chuva da estética relacional - parece desesperado e anêmico em comparação com este.

O trabalho consiste em uma impressionante máquina de falar, que, mesmo estando no silêncio de uma galeria, nunca está totalmente calado: o potencial constante da fala cria rumores de dissidência na mente de cada espectador. Mas quando usado, é o pedido da artista - para que os falantes direcionem suas declarações para a terra - que abre o trabalho em tantas direções. Ele descentraliza o Estado enquanto "ouvinte" e árbitro das queixas públicas e coloca o falante em relação com a terra, o que simultaneamente o empodera e o lembra de sua humildade. Essa é uma ótima combinação quando envolve um discurso político.

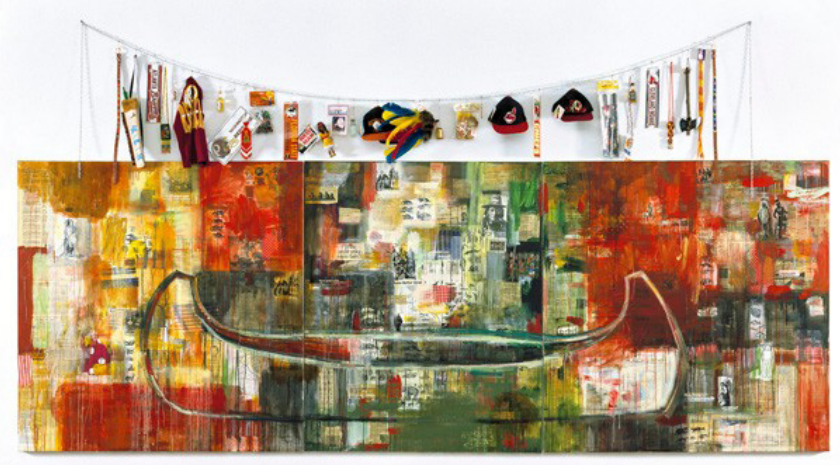

9- Jaune Quick-to-See Smith, Trade (Gifts for Trading Land with White People), 1992.

Como o autorretrato de Durham, este trabalho é constantemente reproduzido por ser bem-sucedido em condensar uma série de ideias e abordagens importantes numa só obra. A primeira vista, põe em contraste 
um ícone do design e da mobilidade Indígena - a canoa - com uma série de objetos kitsch estereotipados, sugerindo a amarga ironia da soberania indígena sobre a terra ter sido substituída por uma contínua desumanização por intermédio de falsas representações e banalizações.

Como em muitas pinturas desse período, esse confronto é apresentado sobre uma colagem na qual fotografias históricas e imagens da cultura pop lutam e competem para atingir a visibilidade da superfície. $\mathrm{O}$ efeito é não apenas colocar histórias alternativas na mesa (este trabalho foi uma das muitas tentativas de subverter celebrações do quinto centenário da chegada de Colombo às Américas), mas pensar diferente e mais fundamentalmente sobre a História. Aqui, a História não é uma narrativa linear, mas uma simultaneidade complexa com um presente problemático.

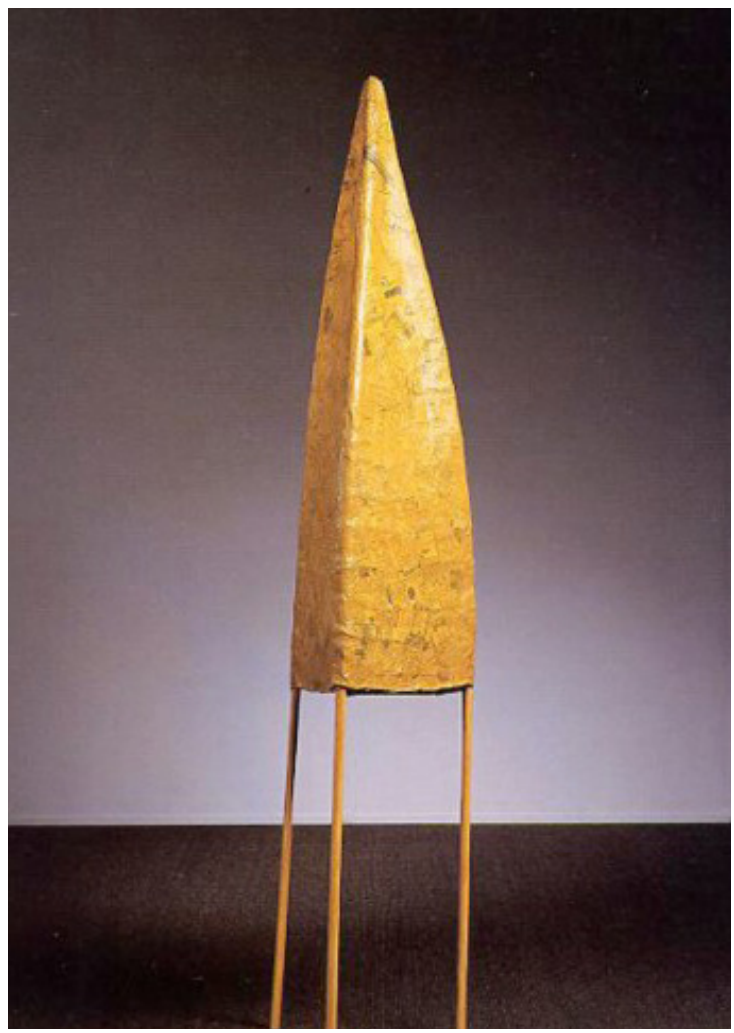

10- Faye HeavyShield, Untitled, 1992.

A primeira vez que vi esse trabalho de HeavyShield foi no catálogo 


\section{ENSAIO}

da exposição do levantamento de arte Indígena de 1992, "Land, Spirit, Power" (Terra, Espírito, Poder) e mais tarde, pessoalmente, na National Gallery do Canadá. Assim que o vi, tive consciência de que estava na presença de um objeto importante, ainda assim, quando tentei articular essa importância para mim mesmo, a linguagem pareceu apenas parcialmente capaz de cumprir a tarefa.

Eu podia ver a forma impecável com que ela combinava a estética da arquitetura da Pradaria (e construções menores) com a austeridade da escultura moderna tardia. Existe um contraste adorável entre materiais banais - camadas de pedacinhos de recortes de jornal quase encobertos por tinta amarela - que de maneira convincente definem uma forma elegante e estão, ao mesmo tempo, contidos dentro da obra. Existe uma sugestão de funcionalidade que, ao final, não pode ser atribuída a nenhuma função em particular.

Em um meio artístico compreensivelmente dominado por trabalhos onde signos e símbolos reconhecíveis muitas vezes dilaceram um ao outro em batalhas pela política de representação, o trabalho de HeavyShield estabeleceu um modelo para uma poética visual das Pradarias contemporâneas, que funcionou com uma gravidade anunciada suavemente. Quanto mais o tempo passa, mais profundamente político parece esse trabalho.

Data de recebimento: 17/05/2018

Data de aceite: $30 / 05 / 2018$ 